\title{
Evaluation of Ball End Micromilling for Ti6Al4V ELI Microneedles Using a Nanoadditive Under MQL Condition
}

\author{
Pavel Celis ${ }^{1}$ - Elisa Vazquez ${ }^{1}$. Cintya G. Soria-Hernández ${ }^{1}$. Diego Bargnani ${ }^{2}$. Ciro A. Rodriguez ${ }^{1}$ - Elisabetta Ceretti ${ }^{2}$. \\ Erika García-López ${ }^{1}$ (i)
}

Received: 15 October 2020 / Revised: 30 July 2021 / Accepted: 13 August 2021 / Published online: 30 August 2021

(c) The Author(s) 2021

\begin{abstract}
The use of nanoadditives in lubricants has gained much attention to the research community due to the enhancement of tribological properties and cooling capabilities. This paper studies the advantages of using a MQL (Minimum Quantity of Lubrication) system and nanoadditive in the manufacture of microneedle arrays in Ti6Al4V ELI alloy. Tungsten carbide ball nose tools with a cutting diameter of $200 \mu \mathrm{m}$ were used in experimental tests. Surface and dimensional characterization was performed to evaluate the impact of a nanoadditive to a vegetable-based oil. Additionally, cutting forces and cutting edge radius (CER) were measured while needles were machined. Experimental tests confirmed that micro end milling with nanoadditives provide slightly better dimensional features and low cutting forces compared to oil. The performance of nanoadditives resulted in a reduction of surface roughness $(\sim 0.3 \mu \mathrm{m})$. Qualitative study of microneedles illustrated burr formation on needle surface manufactured without a nanoadditive solution. Results reveal an increment of CER using low feed rate values $(2.0 \mu \mathrm{m} / \mathrm{flute})$ while a reduction of CER was observed with feed rates up to $2.5 \mu \mathrm{m} / \mathrm{flute}$. Our results indicated that the addition of nanoadditives to vegetable oil promotes a better product surface topography and cutting tool performance.
\end{abstract}

Keywords Micromilling $\cdot$ Ti6Al4V ELI $\cdot$ Microneedles $\cdot$ MQL

\section{Introduction}

Microneedles are tiny sculptured surfaces grouped in arrays created for the indentation of the stratum corneum, which is the outmost layer of the epidermis. Some of the main microneedle features are biocompatibility, a geometric design capable of incising the skin, outstanding dimensional accuracy and good surface quality. According to the US Food and Drug Administration (FDA), dimensional accuracy is evaluated as a measurement of microneedles length, and needle sharpness to perforate into the living layers of the skin [1], which makes dimensional characterization of great importance. These three-dimensional structures are manufactured through several techniques such as molding,

Erika García-López

garcia.erika@tec.mx

1 Tecnologico de Monterrey, Escuela de Ingeniería y Ciencias, Ave. Eugenio Garza Sada 2501 Sur, Monterrey, N.L., Mexico 64849

2 Department of Mechanical and Industrial Engineering, University of Brescia, V. Branze 38, 25123 Brescia, Italy micromilling, laser ablation, and photolithography. The selection of the fabrication technology is based on the material selection (i.e., including polymer, metal, ceramic and glass) which allow to manufacture microneedles with different shapes and sizes [2]. Micromilling is a process capable of manufacturing complex geometries at micro-scale using end mill tools with a cutting diameter less than $1 \mathrm{~mm}$ with applications in automotive, aerospace and medical industries [3]. Thepsonthi et al. [4] fabricated a micro-needle patch prototype using PMMA polymer as workpiece by micromilling. The authors faced the challenges of micromilling polymeric microneedles, however, they achieved the microneedle patch adjusting the toolpath strategies and process parameters. Although titanium alloys are of great interest for the medical field due to their biocompatibility and high corrosion resistance, the micromilling of these alloys relates severe burr formation due to the accelerated tool wear [5]. Additionally, titanium alloys are low thermal diffusive materials, which produce heat accumulation at the tool flute and the produced chip increasing cutting forces and hence dynamic instability [6]. Heat dissipation is achieved by using lubrication at the cutting zone, which reduces tool wear and 
enhances surface quality on the workpiece. In order to dissipate heat in titanium machining, several lubrication methods have emerged. The method of minimum quantity lubrication (MQL) consists on passing air flow through a mixing chamber with the aim of atomizing the coolant stream with microsized particles [7]. This method has improved significantly the surface topography, increasing tool life and reducing burr formation compared to dry cutting in the micromilling of different materials (e.g., SKD61 steel [8], Al5052 [9], and TI6A14V [10]). For micromilling of titanium alloys, studies have reported that MQL is an effective method to reduce cutting temperature, and burr formation in cutting zones [11], which causes tool wear produced by material adhesion [12]. Because of environmental issues, MQL using vegetable -based oil is preferred compared to mineral oils because they do not cause problems to the exposed workers [13]. Schneider et al. explained that ultra-precision manufacturing requires the use of MQL to keep a balance between sustainability and surface quality [14]. In the micromilling of Al-5052 with an end milling tool with a cutting diameter of $200 \mu \mathrm{m}$ and comparing different kinds of lubricants (i.e. oil, ionic liquids, and distilled water), oil was found as an excellent option to get the smoothest machined surface with no evidence of cracks compared with others [9].

The use of nanoadditives has allowed the enhancement of tribological properties and their antifriction performance in lubricants due to their thermal properties [15,
16]. The nano particles of additives improve lubricant performance in the interface between tool and material [17]. Krolczyk et al. [18] revealed that adding nanoparticles in a MQL system contributes in the prolongation of tool life reducing surface roughness due to the minimization of friction coefficient and cutting forces achieving a sustainable machining process. Additionally, MQL leads the concerns of environmental safety and with the minimum utilization of cutting fluid, it results in an economically viable process [19]. Although adding nanoparticles to fluids is expensive, it enhances cooling capabilities making MQL technique a viable alternative for wet machining [7]. Table 1 presents a literature review of MQL lubrication. There are several studies on micromilling of Ti6Al4V alloy with flat end mills analyzing cutting forces and surface roughness, however, from the best of our knowledge no research paper has reviewed the advantages of using MQL and nanoadditives in the manufacturing of sculptured surfaces. This paper presents a micromilling study for the fabrication of microneedles in Ti6Al4V ELI alloy using an MQL system based on nanoadditive - enhanced oil.

Table 1 Literature review of MQL lubrication in Ti6A14V

\begin{tabular}{|c|c|c|c|c|c|c|c|}
\hline References & Geometry & $\begin{array}{l}\text { Tool geometry }\left[d_{c}\right. \\
(\mu \mathrm{m})] \text {, \# flutes }\end{array}$ & $\begin{array}{l}\text { Spindle speed, } N \\
\text { (RPM) }\end{array}$ & $\begin{array}{l}\text { Feed rate, } \\
f_{z}(\mu \mathrm{m} / \\
\text { flute })\end{array}$ & $\begin{array}{l}\text { Depth of } \\
\text { cut, } a_{p} \\
(\mu \mathrm{m})\end{array}$ & $\begin{array}{l}\text { Lubrication method } \\
\text { (Type) [Flow rate] }\end{array}$ & Response \\
\hline [10] & Holes & Drill [700], - & $1,000-10,000$ & $1-7$ & 一 & $\begin{array}{l}\text { MQL, flood cooling } \\
\text { and cryogenic } \\
\text { cooling }\end{array}$ & $\begin{array}{l}\text { Drilling torque and } \\
\text { thrust force }\end{array}$ \\
\hline$[20]$ & Holes & Drill [300],- & 60,000 & $0.16-0.83$ & 400 & MQL (nanofluid) & $\begin{array}{l}\text { Drilling torque and } \\
\text { thrust force }\end{array}$ \\
\hline [6] & Slots & Flat End mill [300], 2 & $20,000-100,000$ & $0.5-5$ & 20 & $\begin{array}{l}\text { Flood cooling (Water } \\
\text { soluble cutting } \\
\text { fluid) }\end{array}$ & $\begin{array}{l}\text { Cutting forces, modal } \\
\text { analysis }\end{array}$ \\
\hline$[11]$ & Channels & Flat end mill [200], 2 & 30,000 & 1.25 & 20 & $\begin{array}{l}\text { Dry, conventional } \\
\text { emulsion and MQL } \\
\text { (Tri-Cool MD1) }\end{array}$ & Surface roughness \\
\hline$[12]$ & Slots & Flat end mill [600], 2 & 40,000 & $0.75-1.5$ & 100 & MQL (Oil) [10 ml/h] & $\begin{array}{l}\text { Surface roughness, } \\
\text { burr formation, tool } \\
\text { wear }\end{array}$ \\
\hline$[21]$ & Slots & Flat end mill [800], 2 & $23,000-40,000$ & $6-12$ & 150 & $\begin{array}{l}\text { Dry, MQL (Oil) } \\
{[15 \mathrm{ml} / \mathrm{h}]}\end{array}$ & $\begin{array}{l}\text { Force components, } \\
\text { minimum uncut } \\
\text { chip thickness }\end{array}$ \\
\hline$[22]$ & Channels & Flat end mill [200], 2 & 30,000 & 0.7 & 20 & MQL (Oil) & $\begin{array}{l}\text { Surface roughness, } \\
\text { width }\end{array}$ \\
\hline$[23]$ & Profile & Flat end mill [500], 2 & $6,300-38,200$ & 6 & 25 & $\begin{array}{l}\text { MQL (nanofluid) [6, } \\
50,100 \mathrm{ml} / \mathrm{h}]\end{array}$ & $\begin{array}{l}\text { Force components, } \\
\text { tool wear, burr } \\
\text { width }\end{array}$ \\
\hline
\end{tabular}




\section{Materials and Methods}

\subsection{Ti6Al4V Alloy and Oil Lubricants}

A base plate of Ti6Al4V ELI (ASTM F136) was used as raw material for the fabrication of microneedle arrays. Titanium plates with a rectangular base of 38.1-mm width and 80-mm length and 9.5- $\mathrm{mm}$ thick were used for experimental trials. The plates were ground in order to guarantee the same thickness in the entire plate and an average surface roughness to accurately establish the zero part in workpiece. The base lubricant is a vegetable- based oil type MD-1 (Tricool, USA). Testing was conducted with lubricant-only solution and nanoadditive with lubricant solution with a concentration of $10 \%$ in weight, according to the supplier (GNA, Mexico).

\subsection{Characterization of the Lubricants}

\subsubsection{Chemical Composition Analysis}

The IR spectrum of the Oil and Oil + nanoadditive were analyzed in the equipment FTIR with the attenuated total reflectance (Perkin-Elmer, Frontier, Waltham, MA, USA) accessory. The samples were measured using a frequency range of 4000 to $400 \mathrm{~cm}^{-1}$, resolution of $8 \mathrm{~cm}^{-1}$ and an average of 16 accumulated scans.

\subsubsection{Morphology Analysis}

An atomic force microscope equipped with a SiNi tip and an SPM (Scanning Probe Microscopy) control station (AFM-3 Multimode, Veeco, USA) was used to evaluate the particles' dispersion. The oil and oil + nanoadditive drops were placed on independent silicon nitride cantilevers. Additionally, the nanoparticles were observed using a field scanning electron microscope (Nova NanoSEM200, FEI, USA) with accelerating voltage of $15 \mathrm{kV}$, and a working distance of $8 \mathrm{~mm}$ in a high vacuum condition. To prepare the sample, the lubricant with nanoparticles was placed in a tube of $15 \mathrm{~mL}$ with hexane in a relation $1: 1$. The solution was centrifuged at $3500 \mathrm{rpm}$ at $25^{\circ} \mathrm{C}$ during $10 \mathrm{~min}$. Then, the supernatant was separated, and $4 \mathrm{~mL}$ of fresh hexane was placed in the tube to centrifuge under the same conditions. This procedure was repeated 3 more times until the lubricant was eliminated. Nanoparticles were suspended in an ethanol solution and placed in a metallic pin at SEM to study the chemical composition and particle diameter. The diameter of the nanoparticles was quantified using Image $\mathbf{J}$ software (Image $1.51 \mathrm{k}$, Bethesda, MD, USA).

\subsubsection{Rheological Parameters}

The rheological measurements of both lubricants (Oil and Oil + nanoadditive) were performed in a rheometer (MCR XX1, Anton Paar, Austria) with a plate-plate geometry of $50-\mathrm{mm}$ in diameter. Lubricants were measured with a shear rate sweep test of $0.1-500 \mathrm{~s}^{-1}$ at 30,100 and $200{ }^{\circ} \mathrm{C}$, respectively. The power law model (Eq. 1) was used to describe the rheological properties of the lubricants.

$\tau=K \gamma^{n}$

where, $\tau$ is shear stress, $K$ is the consistency index $\left(\mathrm{Pa} . \mathrm{s}^{\mathrm{n}}\right), \gamma$ is shear rate, $\mathrm{n}$ is the flow behavior index. Additionally, the Arrhenius equation (Eq. 2) was used to evaluate the effect of temperature on the consistency index $(K)$.

$\ln k=\ln A-\frac{E a}{R T}$

where, $A$ is the constant of model (Pa.s $\left.{ }^{\mathrm{n}}\right), E a$ is the activation energy of flow $\left(\mathrm{kJ} \mathrm{mol}^{-1}\right), R$ is the universal gas constant $\left(8.314 \mathrm{~J} \mathrm{~mol}^{-1} \mathrm{~K}^{-1}\right)$ and $T$ is the temperature $\left({ }^{\circ} \mathrm{K}\right)$.

\subsubsection{Lubricants Stability}

The stability of the nanoparticles in the lubricant was measured using a centrifugation method (ThermoFisher, Sorvall $^{\mathrm{TM}}$ Legend $^{\mathrm{TM}}$ X1R, Waltham, MA, USA). For this technique, $2 \mathrm{~mL}$ of lubricant were centrifuged at $3500 \mathrm{rpm}$ for $30 \mathrm{~min}, 1,2,3,4$ and $5 \mathrm{~h}$, respectively [24].

\subsection{Experimental Setup}

A 3-axis vertical CNC Makino F3 machine with a maximum spindle speed of 30,000 RPM was used to manufacture needle arrays. Mitsubishi tungsten carbide cutting tools with $((\mathrm{Al}, \mathrm{Ti}) \mathrm{N})$ coating were used. A Titanium block with four M3 screws was clamped to a mini-dynamometer $(9256 \mathrm{C} 1$, Kistler, Germany) to measure cutting forces. The dynamometer has a measuring range between -250 to $250 \mathrm{~N}$ in $F x$, $F y$ and $F z$ direction and a working piece clamping area of $39 \mathrm{~mm} \times 80 \mathrm{~mm}$. Zero position was placed on a workpiece surface using a block pattern and a tool laser measuring system (V1031I-O12E-XA, Blum, Germany). Cutting forces were measured with a three-channel charge amplifier Kistler 5814B1 with a sensitivity of $-25.7 \mathrm{pC} / \mathrm{N},-13.0$ $\mathrm{pC} / \mathrm{N}$, and $-26.1 \mathrm{pC} / \mathrm{N}$ for $X, Y$ and $Z$ axis, respectively. The amplifier was connected to a 2110 BNC block connector, which was plugged to a data acquisition card (PCI 6220, NI, USA) to acquire the cutting forces of each channel. A mini-cool nozzle cutting fluid applicator (MC1700, Noga, Israel) was used to supply lubricant in a cutting zone as 
MQL system. The system consists of two separate controls for air and lubricant, which allows the internal mixture of the oil with the compressed air. A magnetic base was mounted on the spindle to address the drop in the cutting zone. The air pressure was fixed to the same level (18 LPM) and the outlet of the MQL system was calibrated to get a flow rate of $10 \mathrm{ml} / \mathrm{h}$ using both lubricants. The MQL nozzle was located about 30-mm from the cutting flute and material interface. The droplet diameter was quantified using an infinite focus microscope (XL200, Alicona, Raaba, Austria) in a range between $50 \mu \mathrm{m}$ and $100 \mu \mathrm{m}$ at the same distance for both lubricants. Figure 1 presents the experimental setup used in the fabrication of needle arrays.

\subsection{Microneedle Arrays and Needle Characterization}

Microneedles were disposed in a linear array of nine needles. Linear configuration was selected to rotate microneedles when dimensional and topography features were measured along the surface. The needle design consisted of a conical geometry with a height of $1000-\mu \mathrm{m}$ and a base diameter of $1000-\mu \mathrm{m}$. Two arrays with nine needles (18 needles) and two

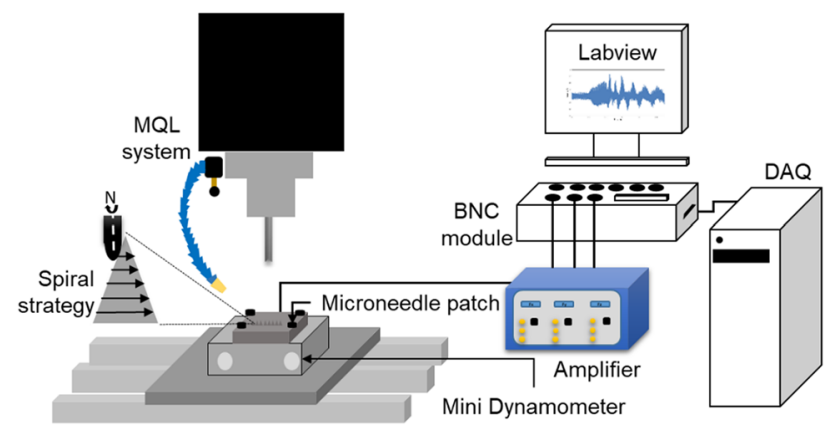

Fig. 1 Experimental setup replicates of each set of experiments were performed. Each set of experiments was manufactured with a new micro-tool.

Microneedles were modeled via CAD software (SolidWorks 2018, DS Solidworks, USA) and then were exported to CAM software (PowerMill 2018, Autodesk, USA) to generate $\mathrm{G}$ code. A vortex milling strategy was implemented to remove material in rough operation and semi-finishing operation. For finishing operation, an optimized constant $\mathrm{Z}$ finishing strategy and a constant $\mathrm{Z}$ finishing with spiral approach from tip needle to base needle were used. Cutting conditions for machining operations are illustrated in Table 2. After the microneedles were manufactured, these were submerged in an ultrasonic bath of isopropyl alcohol for $5 \mathrm{~min}$ and dried with compressed air to remove fine particles adhered to the surface. Geometrical dimensions and surface topography were measured in an infinite focus variation microscope (XL200, Alicona, Raaba, Austria) using a $10 \times$ objective lens and a lateral sampling distance of $0.880 \mu \mathrm{m}$. Needles were placed under a microscope in a horizontal position to inspect average surface roughness along feed direction using the form removal tool from Alicona software. This tool converts needle curve to a flat surface to analyze surface roughness without losing information. The selection of surface roughness filters was made according to the ISO 4288 standard [25]. Height, base diameter and tip diameter were measured each two needles until 18 needles were completed. Each dimension was measured with two replicates. CER measurements were performed using the EdgeMasterX device from Alicona using a $50 \times$ lens and a vertical resolution of $0.050 \mu \mathrm{m}$. Figure 2 illustrates the cutting edge radius measurement, a plane was projected $40 \mu \mathrm{m}$ far from tool tip, because it was the zone observed with the greatest tool wear. A 2D cut view was obtained from EdgeMaster device and CER was measured through the identification of rake and clearance surfaces. Additionally, a qualitative study of microneedles was obtained with

Table 2 Cutting conditions for machining operations

\begin{tabular}{lllll}
\hline Parameter & Unit & Rough & Semi-finish & Finishing \\
\hline Tool geometry & - & Square end mill (MS2SSD0080) & $\begin{array}{l}\text { Square end mill } \\
\text { (MS2SSD0080) }\end{array}$ & $\begin{array}{c}\text { Ball end mill } \\
\text { (MS2S- } \\
\text { BR0010S04) }\end{array}$ \\
Number of flutes & & & 2 & 2 \\
Tool diameter $\left(d_{c}\right)$ & - & 2 & 800 & 200 \\
Spindle speed $(N)$ & $\mu \mathrm{m}$ & 800 & 30,000 & 30,000 \\
Cutting speed $\left(V_{c}\right)$ & $\mathrm{RPM}$ & 30,0000 & 75.40 & 18.85 \\
Feed rate per flute $\left(f_{z}\right)$ & $\mathrm{m} / \mathrm{min}$ & 75.40 & 0.008 & $0.002,0.0025,0.003$ \\
Radial depth per cut $\left(a_{e}\right)$ & $\mu \mathrm{m} /$ tooth & 0.008 & Variable & -- \\
Depth of cut $\left(a_{p}\right)$ & $\mu \mathrm{m}$ & 500 & 30 & 3 \\
Coolant & $\mu \mathrm{m}$ & 30 & & 25 \\
Machining time per array & $\mathrm{min} /$ array & 165 & & 35 \\
\hline
\end{tabular}




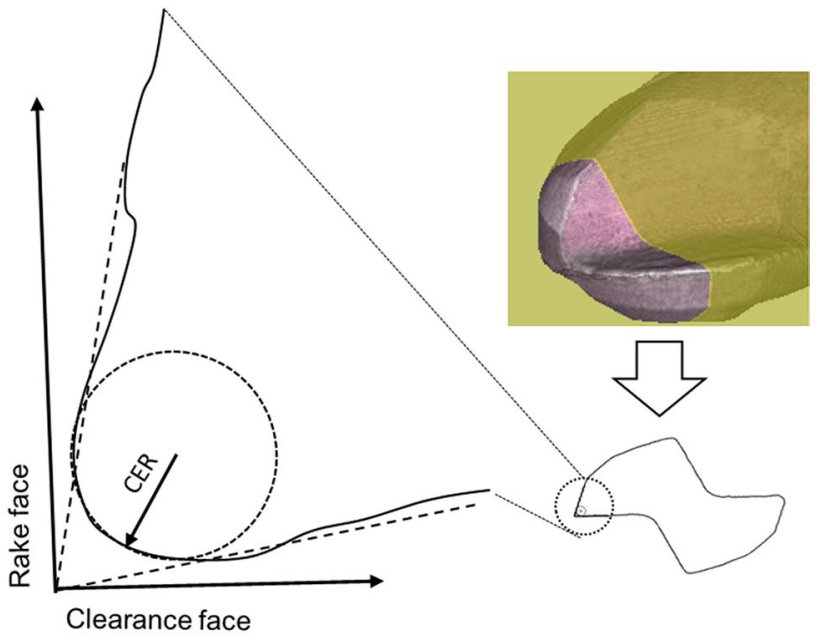

Fig. 2 CER measurement

a scanning electron microscope (SEM) (EVO MA 25, Carl Zeiss, Oberkochen, Germany) in the secondary electron mode and with an accelerating voltage of $10 \mathrm{kV}$.

\section{Results}

\subsection{Lubricant characterization}

\subsubsection{Lubricants Composition}

To analyze their composition, the typical signals and vibration modes of vegetable oils were observed in the FTIR spectrum of oil and oil with nanoadditive (Fig. 3).
At $3006.42 \mathrm{~cm}^{-1}$ we observed a signal corresponding to the stretching of the $=\mathrm{CH}$ (cis) group of the olefinic double bonds, while at $2922.58 \mathrm{~cm}^{-1}$ and at $2853.25 \mathrm{~cm}^{-1}$ we observed the asymmetric and symmetric signals of the stretching - $\mathrm{CH}$ of the methylene group $\left(-\mathrm{CH}_{2}\right)$, respectively. At $1743.1 \mathrm{~cm}^{-1}$ we observed the typical stretching the triglycerides ester group $-\mathrm{C}=\mathrm{O}$, at $1463.46 \mathrm{~cm}^{-1}$ the scissoring bending of $-\mathrm{CH}$ corresponding to the aliphatic groups $\mathrm{CH}_{2}$ and at $1377.65 \mathrm{~cm}^{-1}$ the symmetrical bending of $-\mathrm{CH}$ of the methyl group $\left(-\mathrm{CH}_{3}\right)$ was observed. At the $1237.3,1159.8$ and $1095.54 \mathrm{~cm}^{-1}$ mark, stretching of the esters $-\mathrm{C}-\mathrm{O}$ can be observed and in $722.06 \mathrm{~cm}^{-1}$ the rocking bending vibration of the $-\mathrm{CH}_{2}$ group. The strong molecular interactions of the triglycerides $(\mathrm{C}=\mathrm{O},-\mathrm{CH}$, and $=\mathrm{CH})$ that compose vegetable oils allow them to maintain high viscosity and thermal stability in machined surfaces. Furthermore, the length and polarity of their chains generate molecular films that interact strongly with metal surfaces, reducing friction and wear [26].

\subsubsection{Lubricants Morphology}

The particle size distribution of the metallic particles contained in the vegetable oil was performed using Atomic Force Microscopy (AFM). The cantilever surface profile was processed with Image J software (ImageJ $1.51 \mathrm{k}$, Bethesda, MD, USA) to obtain the total number of particles and size distribution. Figure 4a corresponds to the control image of the oil without particles, while Fig. 4b, corresponds to the oil with particles. The AFM image showed that the metallic nanoparticles were homogeneously distributed over the entire surface of the cantilever, which shows that the metallic
Fig. 3 FTIR spectra of Oil and Oil+ nanoadditive samples

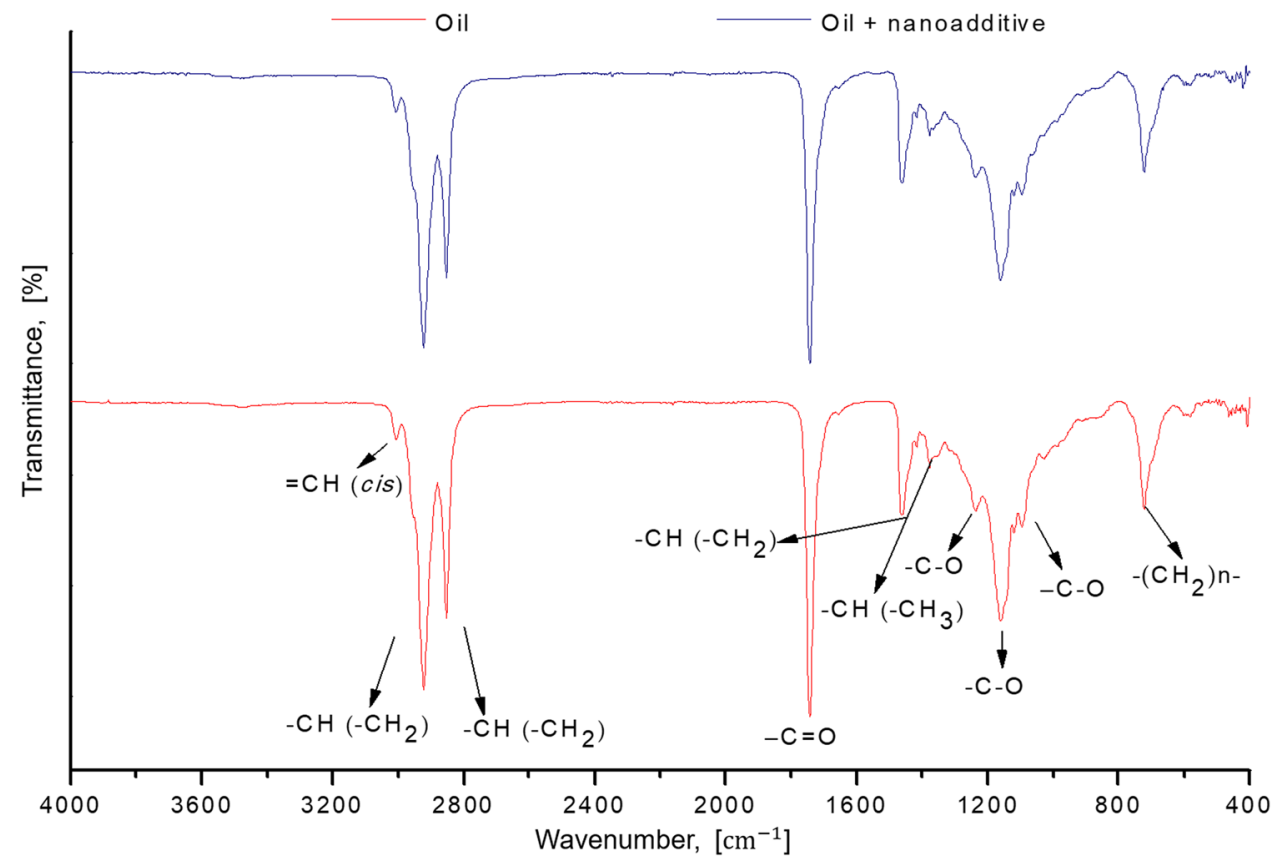



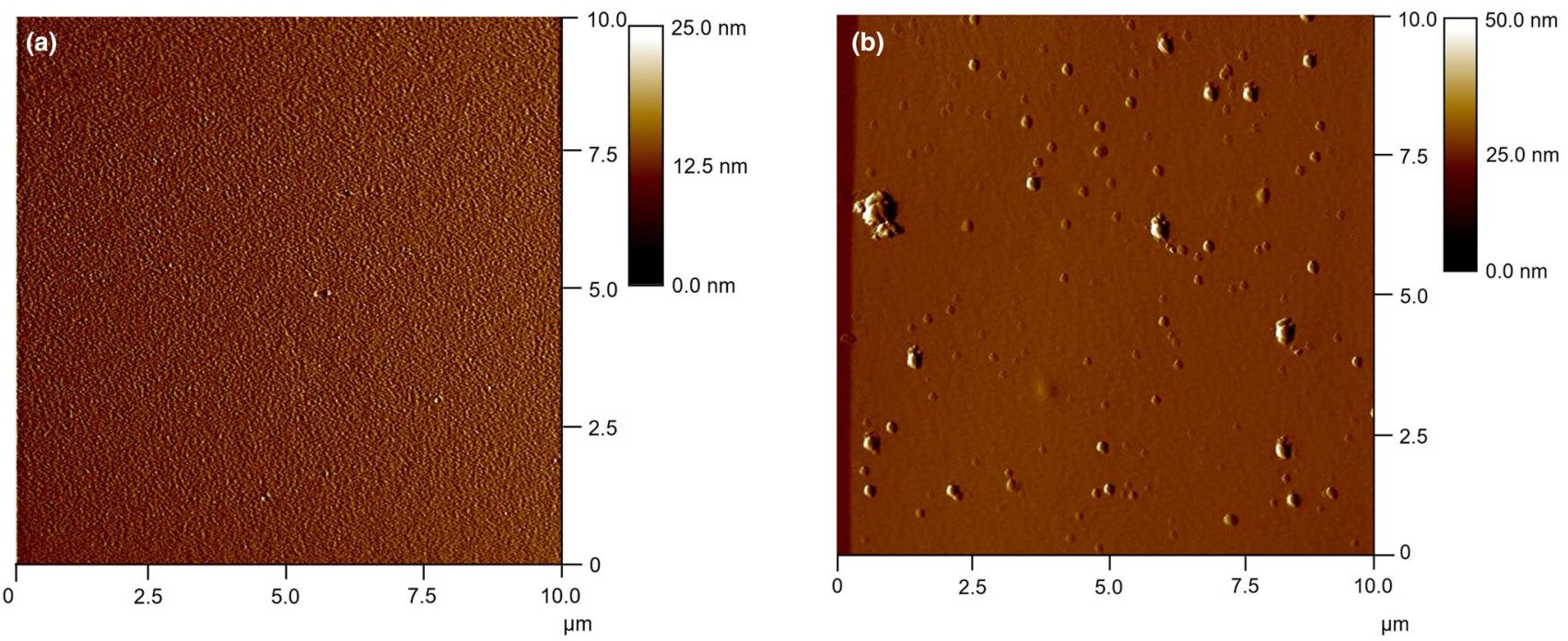

Fig. 4 AFM images of lubricants samples: a particle distribution in Oil, $\mathbf{b}$ particle distribution in Oil + nanoadditive

nanoparticles are homogeneously dispersed in the oil. These characteristics are important since Srivyas and Charoo, [27] reported that the small size and spherical shape of the particles, as well as their adequate dispersion in the fluid, have a repairing, protective film and ball bearing effect that reduce the friction and wear during lubrication.

Furthermore, 200 particles were measured using the SEM microscope. The micrographs showed nanoparticles with a spherical and angular shape, as well as aggregates of the same (Fig. 5a, b), which favors lubrication efficiency, According to Srivyas and Charoo, [27], the sphericity of the nanoparticles equilibrate the high surface energy they experience, allows them to support extreme pressure and a high load capacity, reducing the work and energy required for lubrication. In addition, it causes a ball bearing effect as the nanoparticles roll between surfaces, considerably reducing friction. Figure $5 \mathrm{c}$ presents the size distribution of nanoparticles, it was determined that the diameter of the particles oscillated between 30 and $84 \mathrm{~nm}$. After normalizing the size distribution, it was calculated that the mean diameter of the nanoparticles contained in the oil was $59.2 \pm 0.232 \mathrm{~nm}$. The chemical composition resulted in Carbon (C) 38\% wt., Oxygen (O) 10\%wt., Sulfur (S) 13\%wt., Potassium (K) 2\%wt. and Tungsten (W) 37\%wt.

\subsubsection{Rheology of Lubricant}

The viscosity variation between oil and oil with nanoadditive is shown in Fig. 6. The viscosity of the oil without nanoadditive at 30,100 and $200{ }^{\circ} \mathrm{C}$ was $0.996 \pm 0.001,0.952 \pm 0.002$ and $0.894 \pm 0.001 \mathrm{~Pa} . \mathrm{s}$, respectively. As for the oil with nanoadditive, the viscosity was $0.997 \pm 0.003,0.974 \pm 0.001$ and $0.950 \pm 0.001 \mathrm{~Pa} . \mathrm{s}$ at the same temperatures, respectively
(Fig. 6). This demonstrated that the addition of metallic nanoparticles did not change the viscosity of the oil at $30^{\circ} \mathrm{C}$, since both lubricants had the same viscosity. This appreciation is favorable because Gulzar et al. [28] reported that adding nanoparticles can increase the oil viscosity causing a pressure drop in the lubrication system and higher energy consumption. It was also determined that nanoparticles granted greater stability to viscosity with respect to the change in temperature, since oil's viscosity decreased by 4.42 and $10.24 \%$ at 100 and $200{ }^{\circ} \mathrm{C}$, respectively. The oil with nanoparticles' viscosity was reduced to 2.31 and $4.71 \%$ at the same temperatures, respectively. Therefore, it was determined that adding nanoparticles to the oil reduced approximately $50 \%$ in the viscosity according to the temperature increment.

The Arrhenius Equation was used to quantitatively evaluate the effect of temperature on oil viscosity and oil with nanoadditive. The activation energy $(E a)$ of the oil resulted $756.724 \pm 0.53 \mathrm{~J} / \mathrm{mol}$ and $342.329 \pm 1.12 \mathrm{~J} / \mathrm{mol}$ for the oil with nanoparticles. Therefore, the viscosity of the oil resulted more sensitive to the change of temperature than oil with nanoparticles. This can be explained by the position of nanoparticles in the oil layers which can modify the friction phenomenon from sliding friction to rolling friction.

The frequency constant $(A)$ of the oil was $0.74 \pm 0.01$ Pa.s, while the constant of oil with nanoparticles was $0.87 \pm 0.01$ Pa.s. Using Arrhenius parameters, viscosities for oil and oil with nanoadditive were predicted. The predicted viscosity values for the oil at 30,100 and $200^{\circ} \mathrm{C}$ were $0.999 \pm 0.004,0.945 \pm 0.007$ and $0.897 \pm 0.004 \mathrm{~Pa}$.s, respectively. While the predicted viscosity for the oil with nanoadditive was $0.998 \pm 0.001,0.973 \pm 0.001$ and $0.950 \pm 0.001 \mathrm{~Pa} . \mathrm{s}$ at the same temperatures, respectively. 
Fig. 5 SEM analysis a nanoparticles micrograph $(100,000 \times)$, b nanoparticles micrograph $(200,000 \times)$, c histogram particle size distribution

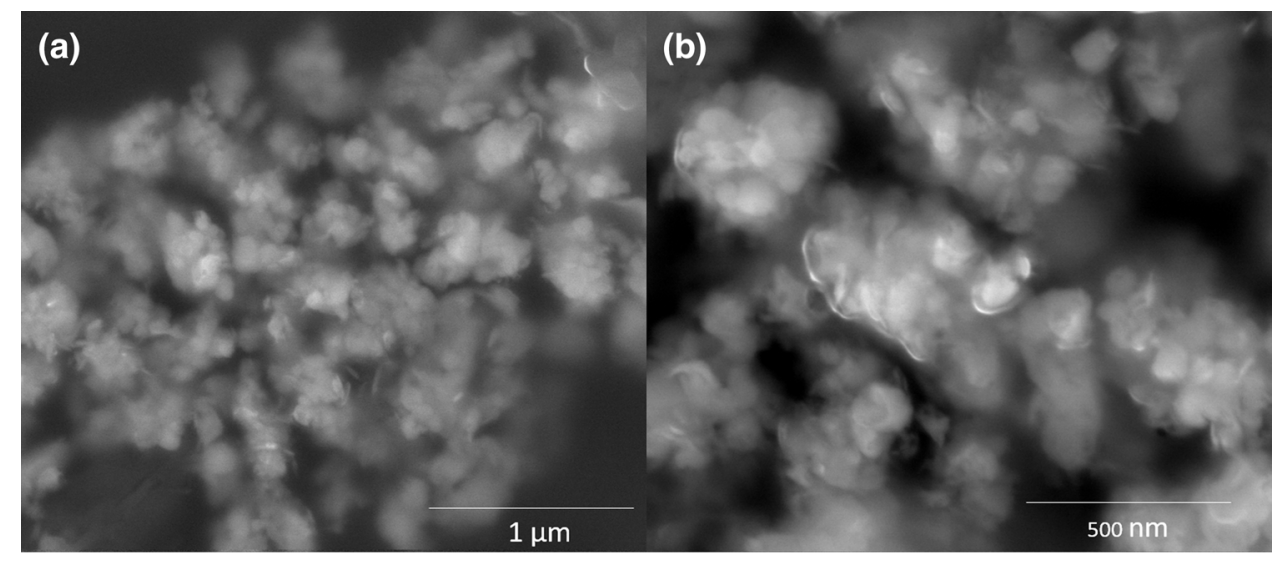

(c)

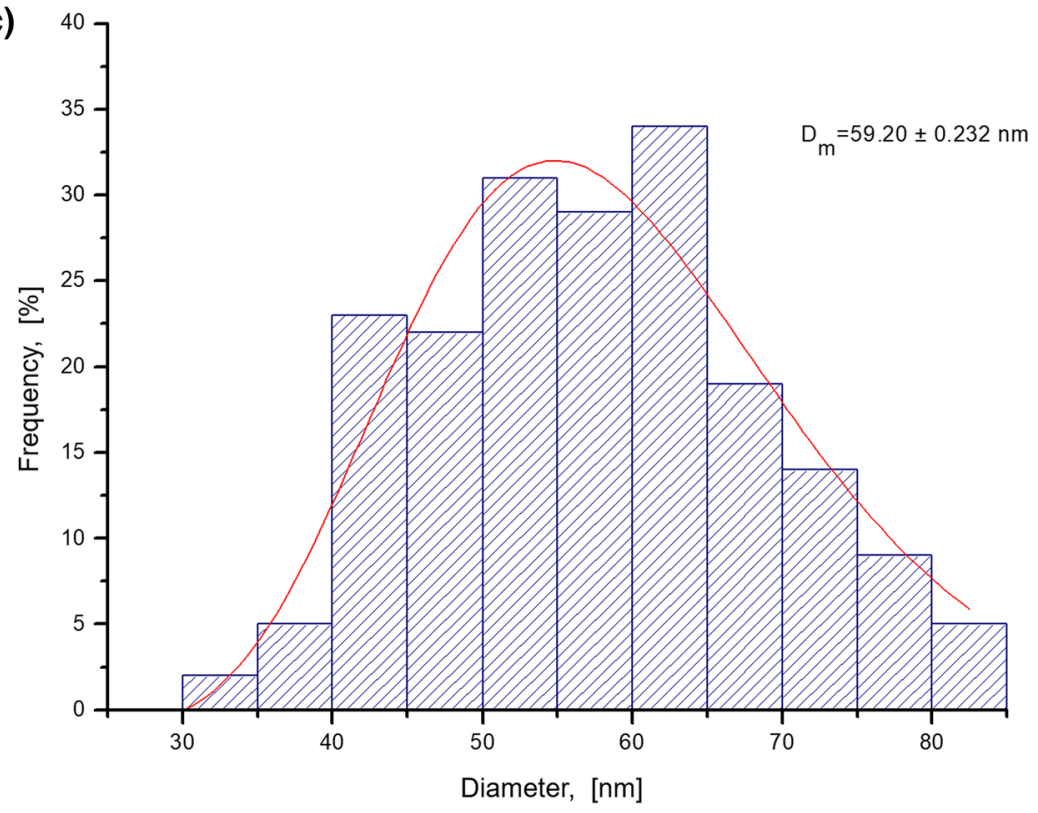

Figure 7 shows that the experimental data of the lubricants viscosity had a good fit with the data predicted by the model $\left(R^{2}=0.986\right.$ and $R^{2}=0.997$ (Oil + nanoadditive lubricant)). These results indicate that the Arrhenius model adequately describes the viscosity variation of lubricants by the effect of temperature.

\subsubsection{Lubricants Stability}

The stability of the metal nanoparticles in the vegetable oil was qualitatively evaluated by applying a centrifugal force for $30 \mathrm{~min}, 1,2,3,4$ and $5 \mathrm{~h}$ (Fig. 8). Samples subjected to centrifugation for $30 \mathrm{~min}, 1$ and $2 \mathrm{~h}$ maintained the stability of the suspension of the metallic nanoparticles intact. The sample centrifuged for $3 \mathrm{~h}$ presented a slight sedimentation of the nanoparticles at the bottom of the tube, which increased as the time of centrifugation increased to 4 and $5 \mathrm{~h}$. Finally, it was possible to determine that after $5 \mathrm{~h}$ of centrifugation at $3500 \mathrm{rpm}$, the lubricant with
Fig. 6 Rheological parameters of Oil and Oil+nanoadditive at 30, 100 and $200^{\circ} \mathrm{C}$ 


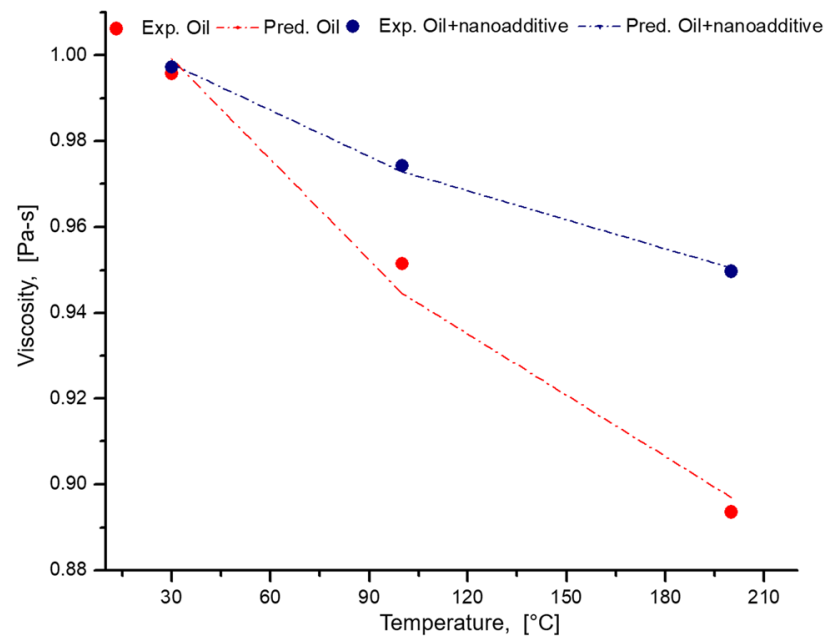

Fig. 7 Experimental viscosity and predicted by the Arrhenius Model for Oil and Oil + nanoadditive at 30,100 and $200{ }^{\circ} \mathrm{C}$

nanoparticles showed a slight loss of suspension of the nanoparticles, but largely preserved the colloidal integrity. Therefore, the oil with nanoadditive has enough stability to provide reliable lubrication performance.

\subsection{Dimensional and Surface Characterization}

For dimensional and surface roughness results, needles were measured every two needles (i.e., 2, 4, 6, 8, 10, 12, 14, 16, 18) with two replications, a mean of these values is plotted with the standard deviation in Figs. 9, 10, 11. For the needle base diameter designed by CAD software $(1000 \mu \mathrm{m})$ (Fig. 9a), the values measured increased as feed per flute increased. Additionally, results showed that farthest values measured from the designed base diameter were obtained using the oil as a lubricant. For needle tip diameter (Fig. 9b), the oil with nanoadditive resulted in the lowest values measured. However, for the low and high values of feed rate, this trend is inverted. For needle height (Fig. 10), nominal height was $1,000 \mu \mathrm{m}$; our results indicate that oil with nanoadditive has a linear tendency from the lowest to the highest value of feed rate used. Nevertheless, values near to designed height are also found with the use of oil and a feed rate of $2.5 \mu \mathrm{m} /$ flute.

For surface roughness measurements, the lowest value of surface roughness was obtained with the use of the lubricant with nanoadditive (Fig. 11). For these results, it is clear that lubricant performance is better incorporating nanoadditive to a solution than oil and it has a direct relation with the needle surface quality. The lowest values of feed rate per

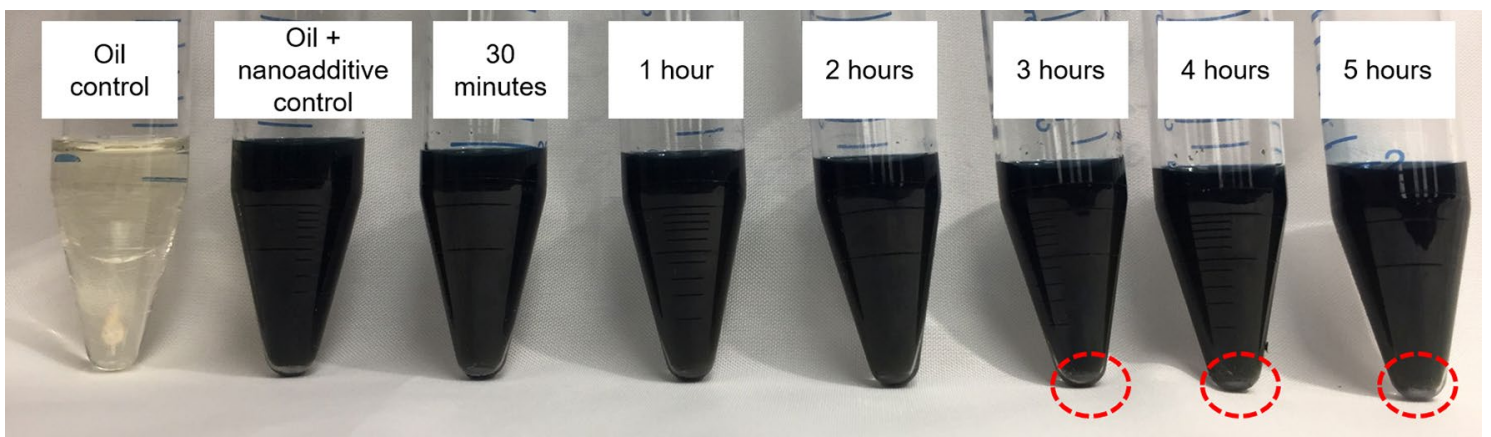

Fig. 8 Oil + nanoadditive stability evaluated by centrifugation at $3500 \mathrm{rpm}$ for $30 \mathrm{~min}, 1,2,3,4$ and $5 \mathrm{~h}$

Fig. 9 Needle geometry measurements; a base diameter, $\mathbf{b}$ tip diameter
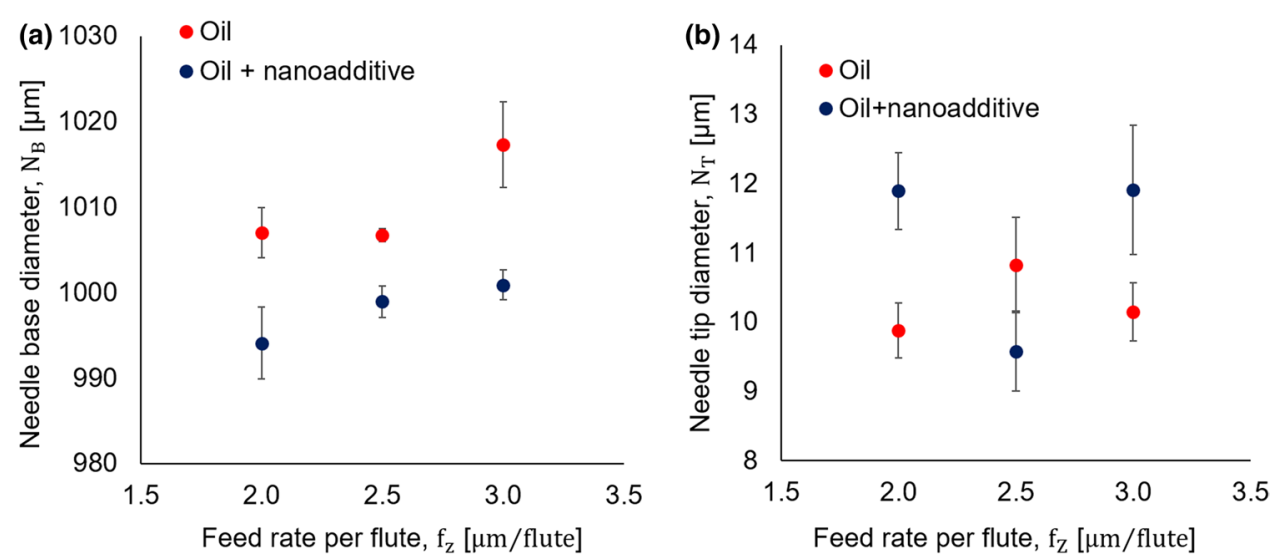


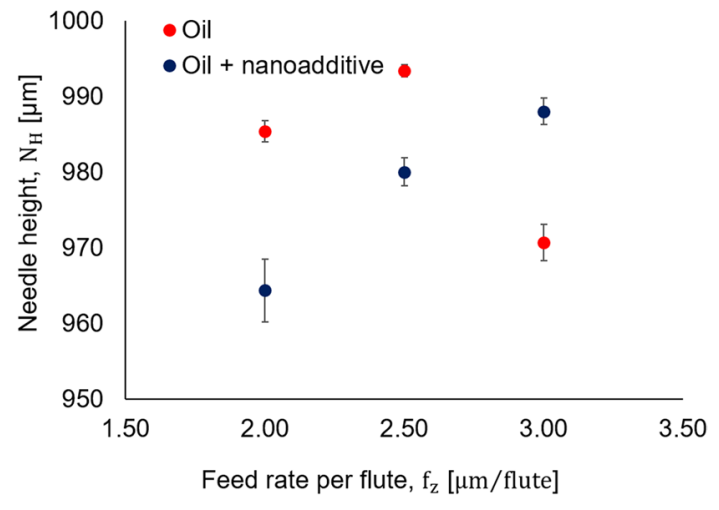

Fig. 10 Needle height

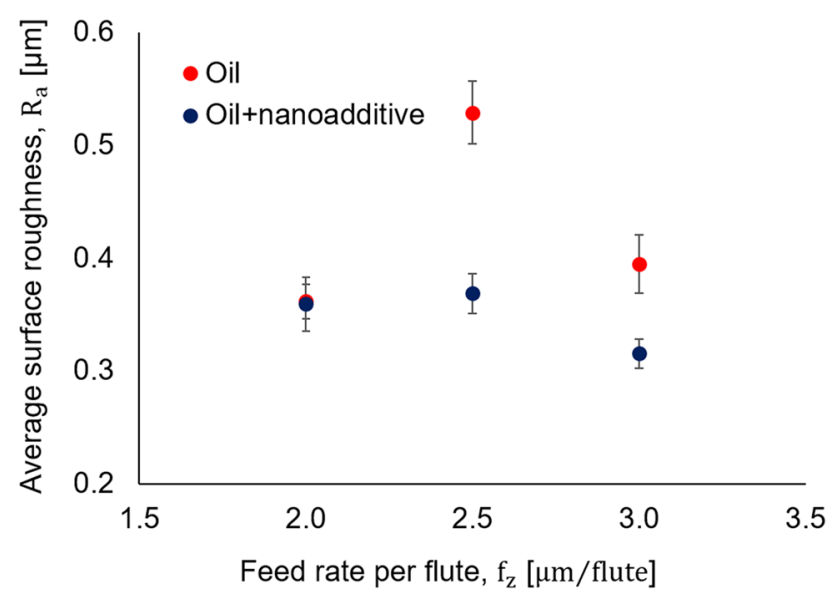

Fig. 11 Needle surface roughness

flute have the same values of surface roughness with both lubricants. The highest values of surface roughness resulted at feed rate of $2.5 \mu \mathrm{m} /$ flute.

Table 3 and 4 present a comparative study of surface topography using oil and oil with nanoadditive. Table 3 presents the upper view of the needles geometry and Table 4 illustrates a zoom-in image of the manufactured needle tip. SEM images (Tables $3 \mathrm{a}$ and $4 \mathrm{a}$ ) illustrate microneedles manufactured with nanoadditive. When needles were zoomed -in, a sharper tip and smaller burrs (white oval) were observed using nanoadditive (Table 4a) compared to needles manufactured with oil (Table 4b). For example, the experiment with a feed rate of $2 \mu \mathrm{m} /$ flute on the sixth needle (Table 4b) has some burrs (white oval) adhered to the surface, while burrs are more evident using the highest feed rate ( $3 \mu \mathrm{m} /$ flute) in needles twelfth and eighteenth (Table $4 \mathrm{~b}$ ). Berestovskyi et al. explained that build -up-edges (BUE) worsens surface finish and increases burr formation, however BUE and wear of the tool can be minimized with coated tools and applying MQL [29]. Additionally, according to Vazquez et al. [22] the use of MQL in microscale allows wetting the tool tip compared to traditional lubrication flood cooling which causes a disordered flow. Their results explain that MQL flow can penetrate the small cutting zone, which allowed heat extraction during machining, reducing friction and removing the chip from the cutting zone. In our experiments, the use of the nanoadditive in oil resulted in microneedles with better surface quality and less burr formation (see Tables 3a and 4a). Besides, BUE formation could be the cause of micro-craters (red oval) caused by material adhesion (Table $4 a, b)$.

\subsection{Cutting Forces and Tool Wear}

After cutting forces were acquired in $X, Y$, and $Z$ direction, the root mean square (RMS) value of all signals was calculated while the needle was cut as follows (Eq. 3):

$F_{R M S}=\sqrt{\frac{1}{N_{S}} \sum_{i=1}^{n} F_{i}^{2}}$

Equation (4) presents the resultant cutting force, which is calculated with the RMS value of each cutting component [30]:

$F_{T}=\sqrt{F_{R M S-X}^{2}+F_{R M S-Y}^{2}+F_{R M S-Z}^{2}}$

According to Colpani et al. [31] the study of cutting force signals is important to analyze the tool life in micromilling, because an increment of the cutting force causes tool breakage. Additionally, Lauro et al. [32] explained that a lower feed provides lower cutting forces and promotes the ploughing effect, which is caused by the increase of temperature in the tool, specific energy and friction coefficient. Particularly, when specific energy is increased smaller ratios are developed between cutting thickness and cutting-edge radius [33]. Therefore, cutting force acquisition can improve the knowledge of the micro-cutting processes [32]. From experimental results, two replicates were averaged, and each replicate was performed using a new tool. The results are presented in Fig. 12, there is no difference between oil and the use of the nanoadditive for lower feed rates $(2.0 \mu \mathrm{m} /$ flute $)$. However, for the 2.5-3.0 $\mu \mathrm{m} /$ flute the use of the lubricant without nanoadditive results in higher cutting forces than if using nanoadditive. This can be explained by the reduction of viscosity (i.e., from $0.996 \pm 0.001$ to $0.894 \pm 0.001$ Pa.s) when temperature is increased, making lubrication less efficient; unlike oil with nanoparticles that keeps its viscosity more stable with temperature.

Figure 13 illustrates the reduction of the cutting edge radius. A percentage of reduction of the CER was calculated as follows (Eq. 5): 
Table 3 Needles manufactured observed in SEM microscope using both lubricants

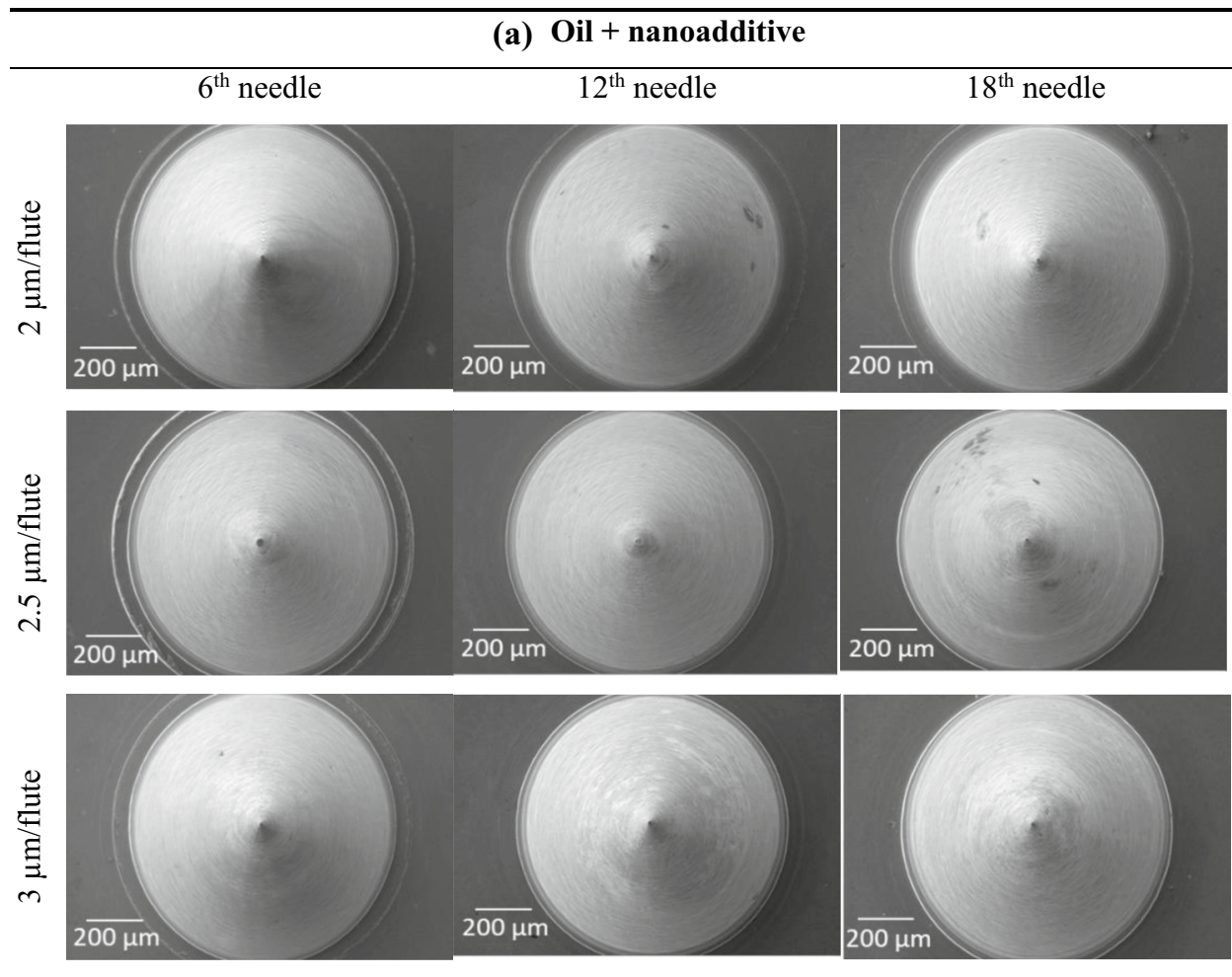

(b) Oil
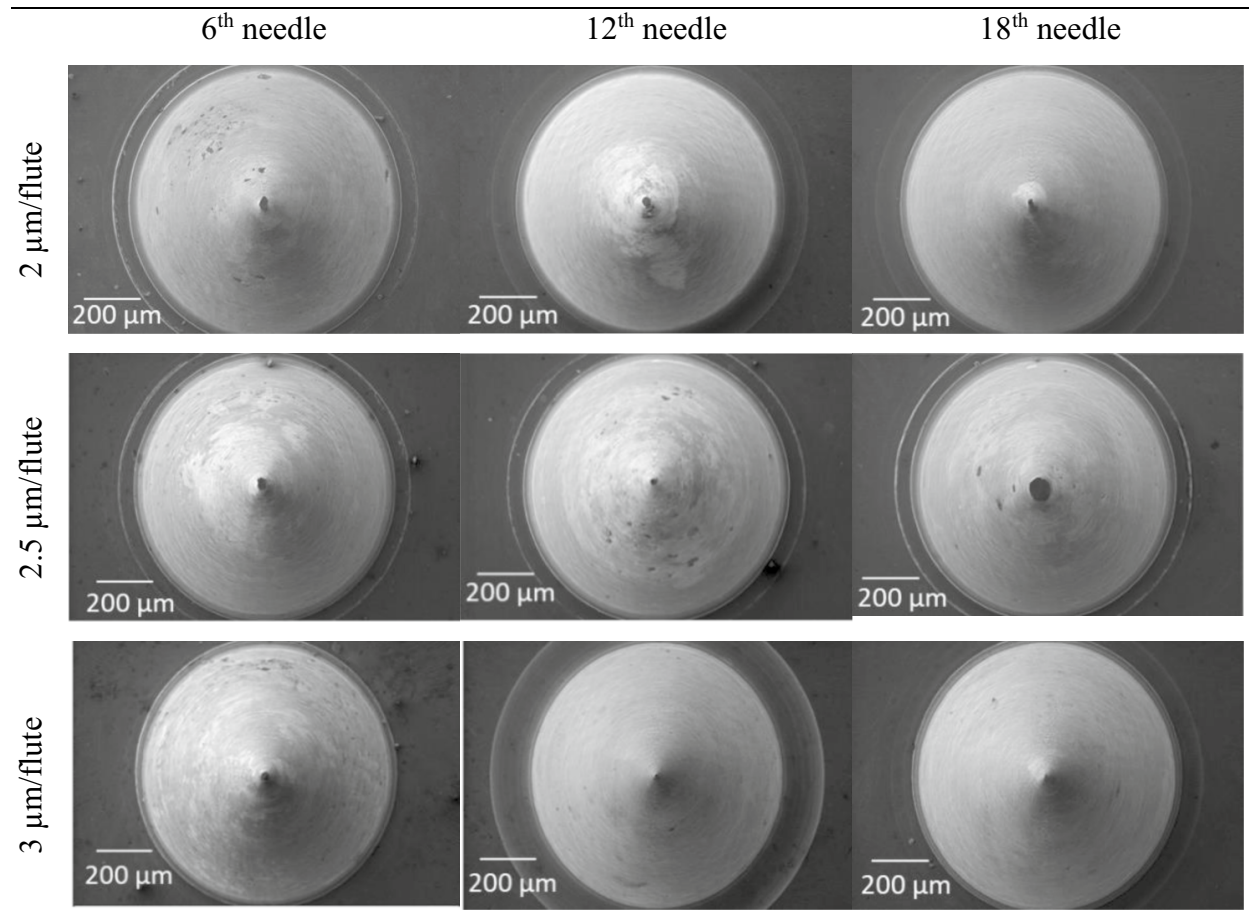

$\mathrm{CER}_{\% R}=\left(\frac{\mathrm{CER}_{I}-\mathrm{CER}_{F}}{\mathrm{CER}_{I}}\right) \times 100$

We observed that the lowest value of feed rate per flute $(2.0 \mu \mathrm{m} /$ flute $)$ resulted in an increase of the cutting edge radius and the highest feed rates caused the biggest reduction in cutting edge radius. Figure 13 illustrates that the cutting edge radius increases with a feed rate of $2.0 \mu \mathrm{m} /$ flute using both lubricants, while feed rates between 2.5 and $3.0 \mu \mathrm{m} /$ flute resulted in a reduction of the cutting edge radius after milling 18 needles. Further experiments can be performed 
Table 4 Needle tip zoom in manufactured observed in SEM microscope using both lubricants

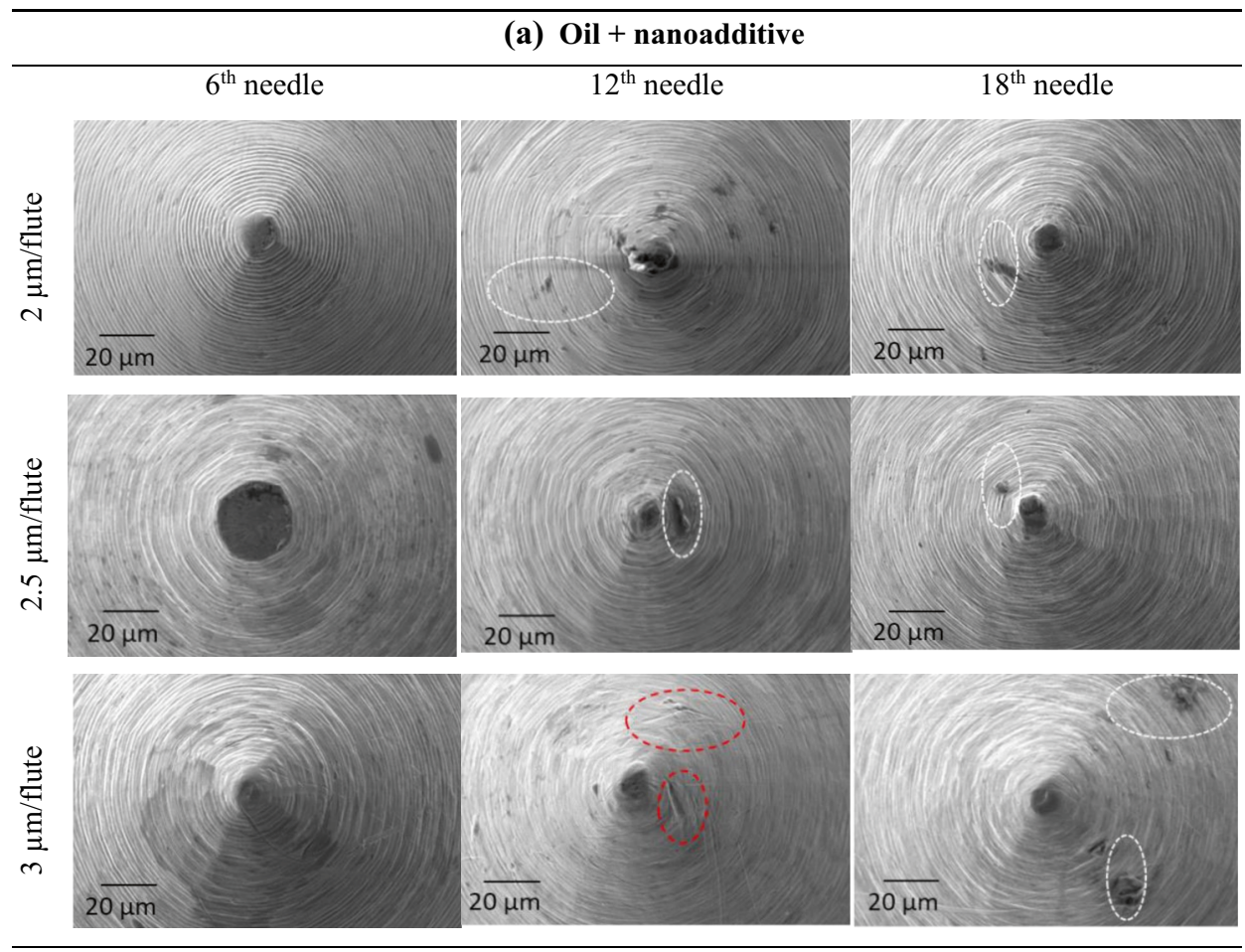

(b) Oil

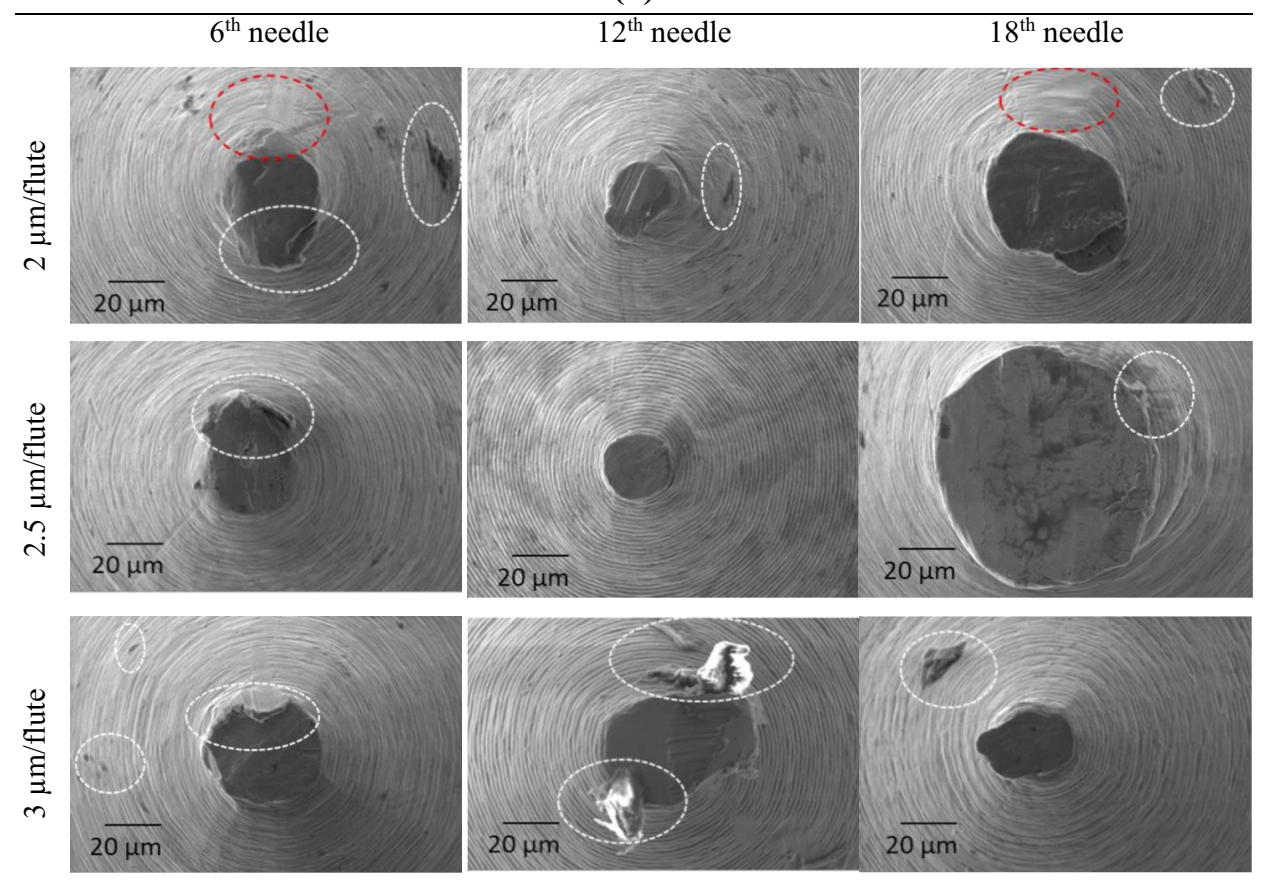

to evaluate chip geometry, the effect of chip thickness and cutting edge on ploughing effect. Figure 14 illustrates CER measurements in new tools and after manufacturing 18 needles. According to Baburaj et al. [34], the main disadvantage of measuring CER in Stereomicroscope and Confocal Microscope is to place the rake and clearance face near and within the same field of view. In our experiments, an infinite focus variation microscope allowed us to compare cutting edge radius measurements using an established plane. However, the differences in new tool batches must be considered, which made difficult the comparison between tools in the micro-size regime. According to Bissaco et al., the cutting edge radius has not been adequately modelled and it is limited by current tool manufacturing methods [35]. Figure 14 shows the raw data of CER measurements. Particularly, CER range in new tools was between 4.83 and $7.68 \mu \mathrm{m}$ (Fig. 14) 


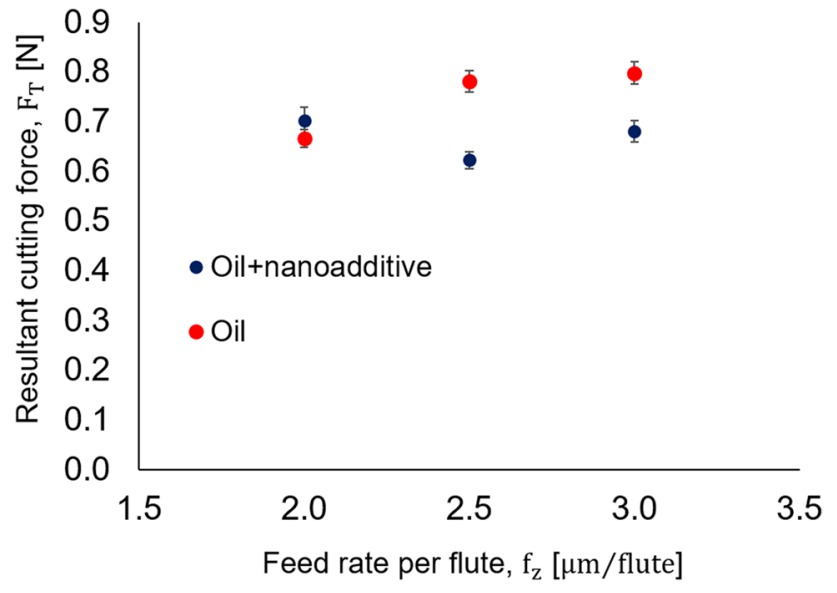

Fig. 12 Resultant cutting force

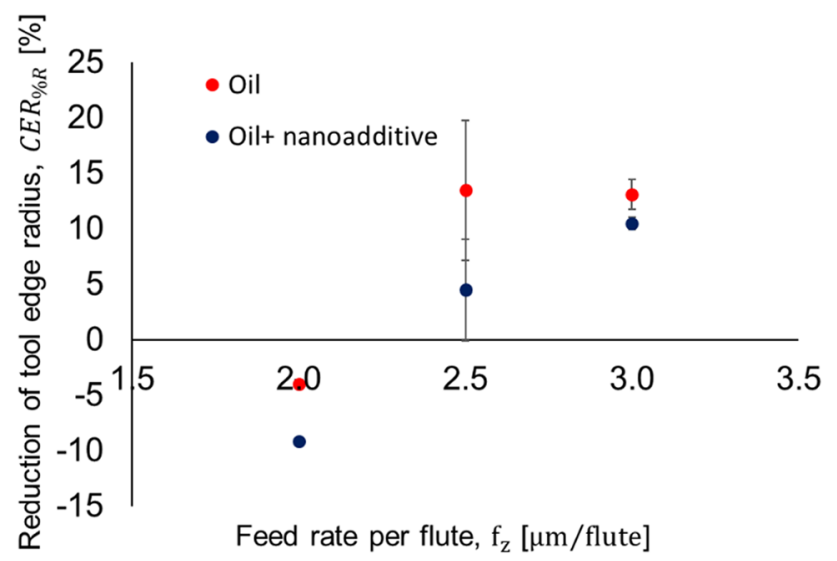

Fig. 13 Reduction on cutting edge radius

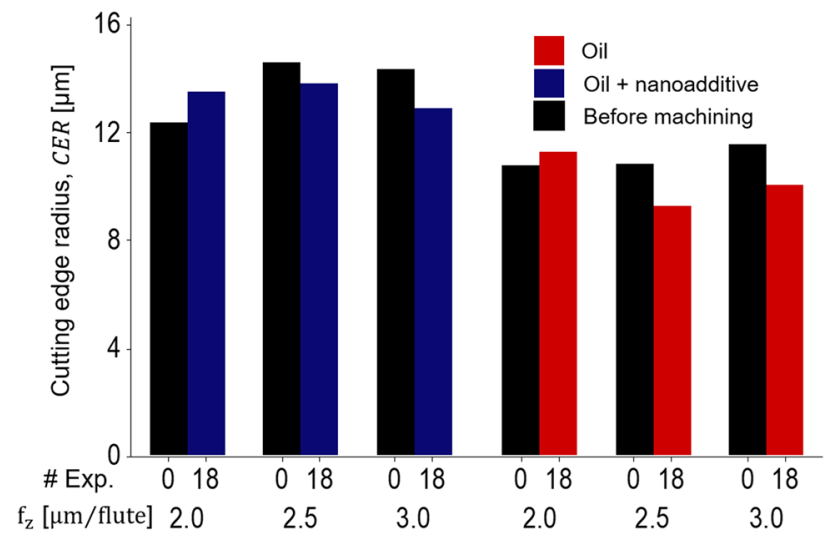

Fig. 14 Cutting edge radius measurements

with a standard deviation of $0.9 \mu \mathrm{m}$. Campos et al. explained the differences in surface roughness of micromilling of pure Titanium and Ti6Al4V which are connected to the corner radius of the tool which vary with tool wear. [36]

\section{Discussion}

The main advantage of micromilling process is it capability to fabricate 3D sculptured surfaces with different geometrical complexity and material [37]. Therefore, it is of great importance the study of needle surface integrity and the influence of adding nanoadditives in an oil vegetablebased lubricant. We explain geometrical differences from Figs. 8 and 9 due to the factors influencing the needle geometry accuracy. For example, setting an erroneous part zero influences the needle height and consequently tool life. Therefore, if part zero is located below the raw material, it would promote differences in height measurements and a dull tip which makes it challenging to approximate the needle tip diameter to $0 \mu \mathrm{m}$. According to Kumar et al. [38], when the cutting diameter is in the micro size regime, this makes it challenging to precisely set the zero position in the $\mathrm{Z}$ axis, therefore traditional methods to stablish it are inadequate for micromilling.

Additionally, in our results, the minimum values of average surface roughness were found at the highest feed rate using oil with nanoadditive. This is due to nanoparticles with a diameter of $59.2 \pm 0232 \mathrm{~nm}$ contained in the oil can effectively work as ball bearing reducing the contact between surfaces.

According to Bissacco et al. [39], an increment in surface roughness and burr formation is caused by a low chip thickness to cutting edge radius ratio. It can be explained by the biaxial compressive stress on material pressing the material to bulge on the surface. Therefore, the best way to increase such ratio is with highest values of feed per tooth, which connote a larger chip. Bissacco et al. [39] explained that using ball nose tools in micromilling promotes attached material to the milled surface caused by a fraction of material bulging aside and in front of the cutting edge which maintains surface and increases surface roughness. In our experiments, extra material can be observed attached to the needle surface when oil was used. Possibly because the viscosity of the oil with nanoparticles remains more stable as the feed rate and temperature increases: there is less friction, wear and the chip is dislodged correctly. For titanium alloys, the tool wear is mainly produced by material adhesion [12]. Therefore, the MQL method provides a good lubrication ability avoiding oxidation wear in cutting zone, which promotes a reduction of the cutting temperature. Vazquez et al. [22] performed experimental and simulation work to compare the traditional lubrication methods (i.e., jet application and MQL technique). Their results indicate that the use of MQL promotes high accuracy, reducing surface roughness, burr formation and tool wear. While tradition flood cooling, influences geometrical shape of microchannels 
producing and error of $20 \%$, which is explained by the not controlled stream. In our experiments, we calculate the geometrical error comparing the base diameter measurement. Our result indicates a geometrical error of $1.7 \%$ using MQL and oil as lubricant while it was reduced to $0.09 \%$ when the nanoadditive was added to the oil using a feed rate of $3 \mu \mathrm{m} /$ flute. It corroborates the advantages of using MQL and the nanoadditive during lubrication.

Tool wear can be quantified ad a difference of cutting diameter compared with new tools; however, some methods have appeared to measure tool edge profile to inspect edge radius. This radius is around 3 to $4 \mu \mathrm{m}$, which makes it a challenge to inspect tool wear at micro-scale [11].

In micromilling, the uncut chip thickness results almost equal or smaller to the cutting edge radius, playing a significant role on chip removal. According to Garcia et al. [40], there is a variation between tool batches, which when combined with the dimensional error induced by the expansion and contraction of the spindle it makes it difficult to characterize cutting edge radius. From our cutting edge radius measurements, some variability among tool batches was observed in new tools. Also, Biermann et al. [41] established that a smaller cutting edge radius causes chatter at small depths of cuts in micromilling because of lower forces. Rezaei et al. [21] performed some experiments in Ti6Al4V material using an end mill with cutting diameter of $0.8 \mathrm{~mm}$ and average cutting edge radii of $6.089 \pm 0.234 \mu \mathrm{m}$. Their results indicate the influence of MQL on the reduction of tool wear, and the enlargement of CER, which is caused by a feed rate greater than $2.1 \mu \mathrm{m} /$ flute. This was corroborated by Vipindas et al., he reported an increase of cutting edge radius caused by tool wear which would cause variation in the minimum uncut chip thickness [42]. In our results, cutting edge radius (Fig. 13) increases using a feed rate of $2.0 \mu \mathrm{m} /$ flute, while $2.5 \mu \mathrm{m} /$ flute resulted with a larger variability between replicates compared with $3.0 \mu \mathrm{m} /$ flute. Rezaei et al. [21] reported that burr formation reduces when feed rate increases, therefore a feed rate of less than $3 \mu \mathrm{m} /$ flute causes large burrs which indicates a high portion of ploughing during chip formation. Additionally, cutting edge radius has an influence on cutting forces and surface quality. According to Aramcharoen et al. [43], ploughing effect is caused by a negative rake angle when the undeformed chip thickness is less than cutting the edge radius. Bissacco et al. [39] explained that the engagement arc is larger in micromilling process than in macro-scale milling due to ploughing effect. Then, the increment of the cutting edge radius causes the extension of the ploughing action along the engagement arc and consequently high surface roughness. If we correlate cutting forces (Fig. 12) and surface roughness (Fig. 11), we can see that in a feed rate per flute of $2 \mu \mathrm{m} / f l u t e$, there is no difference between using the nanoadditive or not. However, for the highest values of feed rate the advantages of the nanoadditive are evident in decreasing cutting forces and surface roughness. This is probably since the viscosity of the oil is considerably reduced at high temperatures (i.e., the highest feed rate) while the oil with nanoparticles is kept stable (see Fig. 6). However, according to Sen et al. [44], further experiments must be performed to evaluate the nanoparticle's toxicity in order to broaden the applicability of MQL with nanoadditives.

\section{Conclusion}

In this study, microneedles arrays were manufactured using micro end mill tools. Dimensional and surface characterization were performed on needles and cutting forces were measured while needles were processed. After the manufacture of 18 needles, tool wear was studied through the measurement of cutting edge radius on ball nose micro tools. The results can be summarized as follows:

- There is a noticeable difference between using oil and oil with nanoadditive. For needle base diameter and tip diameter results, the measurements obtained resulted closest to the nominal values programmed in CAD software using oil with nanoadditive. While for needle height, there is not a clear difference between using oil and oil with nanoadditive. However, it can be attributed to set part zero position in $\mathrm{Z}$ axis before needles were machined.

- Surface topography study revealed formation of large amount of burrs in needles manufactured without nanoadditive. Nanoadditives added in a MQL system enhance cooling capabilities between tool edge and workpiece, which is shown as a reduction of surface roughness and formations of burrs.

- Cutting forces measurements resulted higher using oil without nanoadditive and cutting edge radius measurements were increased using the lowest feed rate $(2.0 \mu \mathrm{m} /$ flute). Also, at higher feed rate values $(2.5-3.0 \mu \mathrm{m} / \mathrm{flute})$, the advantages of using the nanoadditive is clearly the reduction of cutting forces and surface roughness.

- Cutting edge profiles were obtained to measure the cutting edge radii per tool, which resulted different from using a new tool versus a worn tool. After manufacturing 18 microneedles, no cracks nor craters were revealed on the edge of the tool. Therefore, more needle arrays would need to be manufactured to test tool wear until tool breakage.

- We explain the absence of cracks and craters in worn tools due to the formation of a tiny film in the interface between tool and workpiece, which reduces cutting forces allowing the improvement of the tool and therefore 
wear behavior. Future research will address the tribological study.

- In the vegetable oil, all the typical functional groups of fatty acids were determined, whose length and polarity gave an adequate viscosity and thermal stability to be used as a lubricant. As for the nanoparticles, they had a diameter of $59.2 \pm 0232 \mathrm{~nm}$. They were also determined to be homogeneously disperse in the oil and to have adequate colloidal stability for a good lubrication performance. It was also determined that the viscosity of the oil and the oil with nanoparticles have the same viscosity at low temperatures $\left(30{ }^{\circ} \mathrm{C}\right) 0.996 \pm 0.001$ and $0.997 \pm 0.003$ Pa.s, respectively. However, as the temperature increases $\left(200{ }^{\circ} \mathrm{C}\right)$, the viscosity of the oil decreases $10.24 \%$ while the oil with nanoparticles $4.71 \%$, remains more stable. This was quantitatively corroborated with the Arrhenius model, through which it was determined that the activation energy of the oil was $756,724 \pm 0.53 \mathrm{~J} /$ mol while the activation energy of the oil with nanoparticles was $342,329 \pm 1.12 \mathrm{~J} / \mathrm{mol}$. Therefore, the viscosity of the nanoparticle oil is more stable to the effect of temperature and has a higher lubrication performance during MQL.

Acknowledgements We would like to thank Edgar Raygoza from Global Nano Additives (GNA) for the preparation of the lubricant with nanoadditives used in the development of the experiments.

Author Contributions EG-L: Conceptualization, Formal analysis, Investigation, Methodology, Writing -original draft. EV: Conceptualization, Funding acquisition, Investigation, Writing-review and editing. EC: Funding acquisition, Resources, Writing-review and editing. CAR: Funding acquisition, Resources, Writing-review and editing. DB: Investigation. CS-H: Investigation, Writing-review and editing. PC: Investigation.

\section{Declarations}

Conflict of interest The authors declare no conflict of interest.

Open Access This article is licensed under a Creative Commons Attribution 4.0 International License, which permits use, sharing, adaptation, distribution and reproduction in any medium or format, as long as you give appropriate credit to the original author(s) and the source, provide a link to the Creative Commons licence, and indicate if changes were made. The images or other third party material in this article are included in the article's Creative Commons licence, unless indicated otherwise in a credit line to the material. If material is not included in the article's Creative Commons licence and your intended use is not permitted by statutory regulation or exceeds the permitted use, you will need to obtain permission directly from the copyright holder. To view a copy of this licence, visit http://creativecommons.org/licenses/by/4.0/.

\section{References}

1. FDA. (2017). Regulatory considerations for microneedling devices FDA-2017-D-4792 (pp. 1-12). FDA.

2. Indermun, S., Luttge, R., Choonara, Y. E., Kumar, P., Du Toit, L. C., Modi, G., et al. (2014). Current advances in the fabrication of microneedles for transdermal delivery. Journal of Controlled Release, 185, 130-138. https://doi.org/10.1016/j.jconrel.2014.04. 052

3. Wan, Y., Cheng, K., \& Sun, S. (2013). An innovative method for surface defects prevention in micro milling and its implementation perspectives. Proceedings of the Institution of Mechanical Engineers Part J, 227, 1347-1355. https://doi.org/10.1177/13506 50113492507

4. Thepsonthi, T., Milesi, N., \& Özel T. (2012). Design and prototyping of micro-needle arrays for drug delivery using customized tool-based micro-milling process. In: Proceedings of the 1st International Conference on Design and Processes for Medical Devices, Brescia, Italy

5. Thepsonthi, T., \& Özel, T. (2014). An integrated toolpath and process parameter optimization for high-performance micromilling process of $\mathrm{Ti}-6 \mathrm{Al}-4 \mathrm{~V}$ titanium alloy. Journal of Advanced Manufacturing Technology, 75, 57-75. https://doi. org/10.1007/s00170-014-6102-2

6. Mittal, R. K., Kulkarni, S. S., \& Singh, R. (2018). Characterization of Lubrication sensitivity on dynamic stability in high-speed micromilling of Ti-6Al-4V. International Journal of Mechanical Sciences, 142-143, 51-65. https://doi.org/10. 1016/j.ijmecsci.2018.04.038

7. Sharma, A. K., Tiwari, A. K., \& Dixit, A. R. (2016). Effects of Minimum Quantity Lubrication (MQL) in machining processes using conventional and nanofluid based cutting fluids: a comprehensive review. Journal of Cleaner Production, 127, 1-18. https://doi.org/10.1016/j.jclepro.2016.03.146

8. Li, K. M., \& Chou, S. Y. (2010). Experimental evaluation of minimum quantity lubrication in near micro-milling. Journal of Materials Processing Technology, 210, 2163-2170. https://doi. org/10.1016/j.jmatprotec.2010.07.031

9. Pham, M. Q., Yoon, H. S., Khare, V., \& Ahn, S. H. (2014). Evaluation of ionic liquids as lubricants in micro milling. Process capability and sustainability. Journal of Cleaner Production, 76, 167-173. https://doi.org/10.1016/j.jclepro.2014.04.055

10. Perçin, M., Aslantas, K., Ucun, I., Kaynak, Y., \& Çicek, A. (2016). Micro-drilling of Ti-6Al-4V alloy: The effects of cooling/lubricating. Precision Engineering, 45, 450-462. https:// doi.org/10.1016/j.precisioneng.2016.02.015

11. Vazquez, E., Gomar, J., Ciurana, J., \& Rodríguez, C. A. (2015). Analyzing effects of cooling and lubrication conditions in micromilling of Ti6Al4V. Journal of Cleaner Production, 87, 906-913. https://doi.org/10.1016/j.jclepro.2014.10.016

12. Zheng, X., Liu, Z., Chen, M., \& Wang, X. (2013). Experimental study on micro-milling of Ti6Al4V with minimum quantity lubrication. International Journal of Nanomanufacturing, 9, 570-582. https://doi.org/10.1504/IJNM.2013.057600

13. Revuru, R. S., Posinasetti, N. R., Vsn, V. R., \& Amrita, M. (2017). Application of cutting fluids in machining of titanium alloys: A review. International Journal of Advanced Manufacturing Technology, 91, 2477-2498. https://doi.org/10.1007/ s00170-016-9883-7

14. Schneider, F., Das, J., Kirsch, B., Linke, B., \& Aurich, J. C. (2019). Sustainability in ultra precision and micro machining: A review. International Journal of Precision Engineering and Manufacturing-Green Technology, 6, 601-610. https://doi.org/ 10.1007/s40684-019-00035-2 
15. Wang, Y., Li, C., Zhang, Y., Li, B., Yang, M., Zhang, X., et al. (2017). Comparative evaluation of the lubricating properties of vegetable-oil-based nanofluids between frictional test and grinding experiment. Journal of Manufacturing Processes, 26, 94-104. https://doi.org/10.1016/j.jmapro.2017.02.001

16. Pervaiz, S., Anwar, S., Qureshi, I., \& Ahmed, N. (2019). Recent advances in the machining of titanium alloys using minimum quantity lubrication (MQL) based techniques. International Journal of Precision Engineering and Manufacturing-Green Technology, 6, 133-145. https://doi.org/10.1007/ s40684-019-00033-4

17. Xie, H., Jiang, B., Hu, X., Peng, C., Guo, H., \& Pan, F. (2017). Synergistic effect of MoS2 and $\mathrm{SiO} 2$ nanoparticles as lubricant additives for magnesium alloy-steel contacts. Nanomaterials, 7, 154. https://doi.org/10.3390/nano7070154

18. Krolczyk, G. M., Maruda, R. W., Krolczyk, J. B., Wojciechowski, S., Mia, M., Nieslony, P., et al. (2019). Ecological trends in machining as a key factor in sustainable production: A review. Journal of Cleaner Production, 218, 601-615. https://doi.org/10. 1016/j.jclepro.2019.02.017

19. Sen, B., Hussain, S. A. I., Mia, M., Mandal, U. K., \& Mondal, S. P. (2019). Selection of an ideal MQL-assisted milling condition: An NSGA-II-coupled TOPSIS approach for improving machinability of Inconel 690. International Journal of Advanced Manufacturing Technology, 103, 1811-1829. https://doi.org/10.1007/ s00170-019-03620-6

20. Nam, J., \& Lee, S. W. (2018). Machinability of titanium alloy (Ti-6Al-4V) in environmentally-friendly micro-drilling process with nanofluid minimum quantity lubrication using nanodiamond particles. International Journal of Precision Engineering and Manufacturing-Green Technology, 5, 29-35. https://doi.org/10. 1007/s40684-018-0003-z

21. Rezaei, H., Sadeghi, M. H., \& Budak, E. (2018). Determination of minimum uncut chip thickness under various machining conditions during micro-milling of Ti-6Al-4V. International Journal of Advanced Manufacturing Technology, 95, 1617-1634. https:// doi.org/10.1007/s00170-017-1329-3

22. Vazquez, E., Kemmoku, D. T., Noritomi, P. Y., Da Silva, J. V. L., \& Ciurana, J. (2014). Computer fluid dynamics analysis for efficient cooling and lubrication conditions in micromilling of Ti6Al4V alloy. Materials and Manufacturing Processes, 29, 1494-1501. https://doi.org/10.1080/10426914.2014.941864

23. Kumar, A. S., Deb, S., \& Paul, S. (2020). Tribological characteristics and micromilling performance of nanoparticle enhanced water based cutting fluids in minimum quantity lubrication. Journal of Manufacturing Processes, 56, 766-776. https://doi.org/10.1016/j. jmapro.2020.05.032

24. Yu, W., \& Xie, H. (2012). A review on nanofluids: Preparation, stability mechanisms, and applications. Journal of Nanomaterials. https://doi.org/10.1155/2012/435873

25. ISO-Standards. (2006). DS/EN ISO 4288 Geometrical product specifications (GPS) surface texture: profile method rules and procedures for the assessment of surface texture. Ds-handb. 114.52006 Geom. Prod. specifications, 2006, pp. 310-34.

26. Vaibhav Koushik, A. V., Narendra Shetty, S., \& Ramprasad, C. (2012). Vegetable oil-based metal working fluids: A review. International Journal on Theoretical and Applied Research in Mechanical Engineering, 1, 95-101.

27. Srivyas, P. D., \& Charoo, M. S. (2018). A review on tribological characterization of lubricants with nano additives for automotive applications. Tribology in Industry, 40, 594-623. https://doi.org/ 10.24874/ti.2018.40.04.08

28. Gulzar, M., Masjuki, H. H., Kalam, M. A., Varman, M., Zulkifli, N. W. M., Mufti, R. A., et al. (2016). Tribological performance of nanoparticles as lubricating oil additives. Journal of Nanoparticle Research. https://doi.org/10.1007/s11051-016-3537-4
29. Berestovskyi, D., Hung, W. N. P., \& Lomeli, P. (2014). Surface finish of ball-end milled microchannels. The Journal of Micro and Nano-Manufacturing, 2, 1-10. https://doi.org/10.1115/1.4028502

30. Coppel, R., Abellan-Nebot, J. V., Siller, H. R., Rodriguez, C. A., \& Guedea, F. (2016). Adaptive control optimization in micromilling of hardened steels: evaluation of optimization approaches. International Journal of Advanced Manufacturing Technology, 84, 2219-2238. https://doi.org/10.1007/s00170-015-7807-6

31. Colpani, A., Fiorentino, A., Ceretti, E., \& Attanasio, A. (2019). Tool wear analysis in micromilling of titanium alloy. Precision Engineering, 57, 83-94. https://doi.org/10.1016/j.precisioneng. 2019.03.011

32. Lauro, C. H., Ribeiro Filho, S. L. M., Brandão, L. C., \& Davim, J. P. (2016). Analysis of behaviour biocompatible titanium alloy (Ti-6Al-7Nb) in the micro-cutting. Journal of the International Measurement Confederation, 93, 529-540. https://doi.org/10. 1016/j.measurement.2016.07.059

33. De Oliveira, F. B., Rodrigues, A. R., Coelho, R. T., \& De Souza, A. F. (2015). Size effect and minimum chip thickness in micromilling. International Journal of Machine Tools and Manufacture, 89, 39-54. https://doi.org/10.1016/j.ijmachtools.2014.11.001

34. Baburaj, M., Ghosh, A., \& Shunmugam, M. S. (2017). Study of micro ball end mill geometry and measurement of cutting edge radius. Precision Engineering, 48, 9-17. https://doi.org/10.1016/j. precisioneng.2016.10.008

35. Bissacco, G., Hansen, H. N., \& Slunsky, J. (2008). Modelling the cutting edge radius size effect for force prediction in micro milling. CIRP Annals, 57, 113-116. https://doi.org/10.1016/j.cirp. 2008.03.085

36. de Campos, F. O., Araujo, A. C., \& Kapoor, S. G. (2019). Experimental Comparison of Micromilling Pure Titanium and Ti-6Al4V. Journal of Micro and Nano-Manufacturing. https://doi.org/ $10.1115 / 1.4043501$

37. Rodrigues, A. R., \& Jasinevicius, R. G. (2016). Machining scale: Workpiece grain size and surface integrity in micro end milling. Microfabrication and Precision Engineering. https://doi.org/10. 1016/B978-0-85709-485-8.00002-4

38. Kumar, M., Dotson, K., \& Melkote, S. N. (2010). An experimental technique to detect tool-workpiece contact in micromilling. Journal of Manufacturing Processes, 12, 99-105. https://doi.org/10. 1016/j.jmapro.2010.08.001

39. Bissacco, G., Hansen, H. N., \& De Chiffre, L. (2005). Micromilling of hardened tool steel for mould making applications. Journal of Materials Processing Technology, 167, 201-207. https://doi. org/10.1016/j.jmatprotec.2005.05.029

40. Garcia-Garcia, G., Vázquez, E. V., Siller, H. R., Ruiz-Huerta, L., \& Caballero-Ruiz, A. (2017). Calibration of ball nose micro end milling operations for sculptured surfaces machining. International Journal of Machining and Machinability of Materials, 19, 587-605. https://doi.org/10.1504/IJMMM.2017.088898

41. Biermann, D., \& Baschin, A. (2009). Influence of cutting edge geometry and cutting edge radius on the stability of micromilling processes. Production Engineering, 3, 375-380. https://doi.org/ 10.1007/s11740-009-0188-7

42. Vipindas, K., Anand, K. N., \& Mathew, J. (2018). Effect of cutting edge radius on micro end milling: Force analysis, surface roughness, and chip formation. International Journal of Advanced Manufacturing Technology, 97, 711-722. https://doi.org/10.1007/ s00170-018-1877-1

43. Aramcharoen, A., Mativenga, P. T., Yang, S., Cooke, K. E., \& Teer, D. G. (2008). Evaluation and selection of hard coatings for micro milling of hardened tool steel. International Journal of Machine Tools and Manufacture, 48, 1578-1584. https://doi.org/ 10.1016/j.ijmachtools.2008.05.011

44. Sen, B., Mia, M., Krolczyk, G. M., Mandal, U. K., \& Mondal, S. P. (2021). Eco-friendly cutting fluids in minimum quantity 
lubrication assisted machining: a review on the perception of sustainable manufacturing. Korean Society for Precision Engineering. https://doi.org/10.1007/s40684-019-00158-6

Publisher's Note Springer Nature remains neutral with regard to jurisdictional claims in published maps and institutional affiliations.

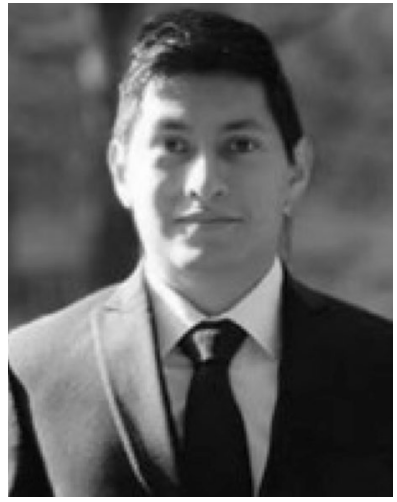

Pavel Celis received his bachelor degree in Industrial Design and his M.Sc. in Manufacturing Systems from Tecnologico de Monterrey. He currently works in the machine tool industry.
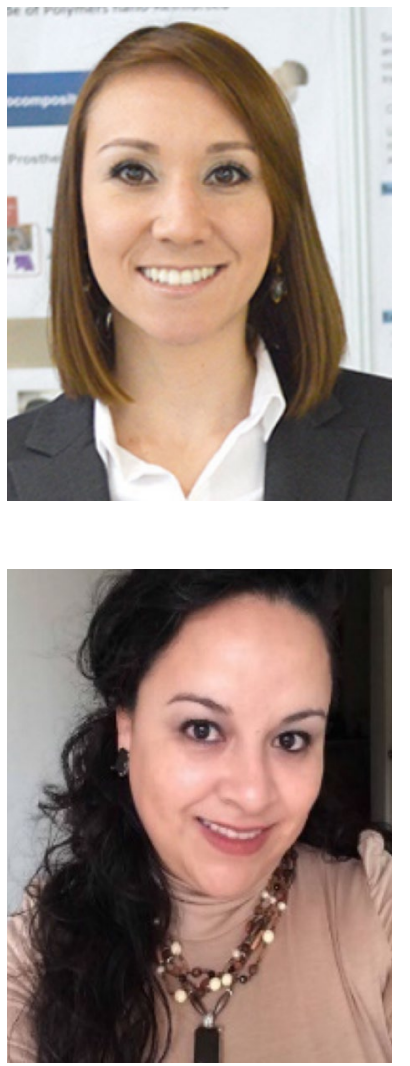

Cintya G. Soria-Hernández received the M.Sc. from Universidad Autonoma de Chihuahua and Ph.D. from Tecnologico de Monterrey. Her current research interests include synthesis of biomaterials, metallic nanoparticles, nanofibers and magnetoreological gels. She currently works in the advanced materials laboratory at Tecnologico de Monterrey.

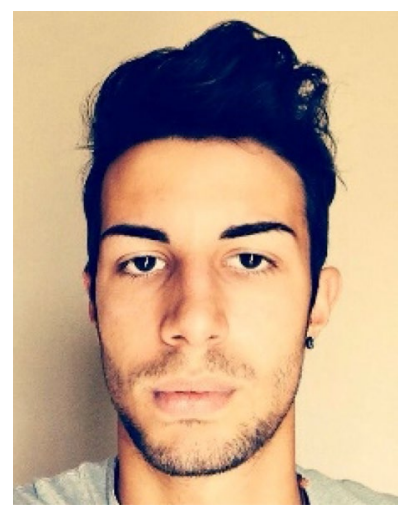

Diego Bargnani received his bachelor degree as industrial engineer and his master degree in Engineering and Industrial Management from University of Brescia. He performed his experimental work by his master thesis project at Tecnologico de Monterrey.

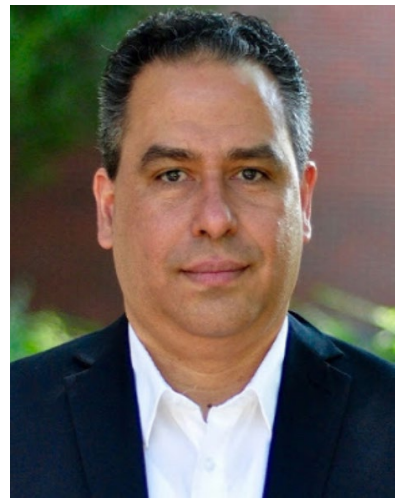

Ciro A. Rodriguez holds a B.S. in Mechanical Engineering from The University of Texas at Austin and a Ph.D. from The Ohio State University. He worked in the automotive and machine tool industry. He is Visiting Scientist at the Osteoengineering Lab of The Ohio State University. He is currently Professor at the Department of Mechanical Engineering and Advances Materials at Tecnologico de Monterrey. He leads the research group in advanced manufacturing.

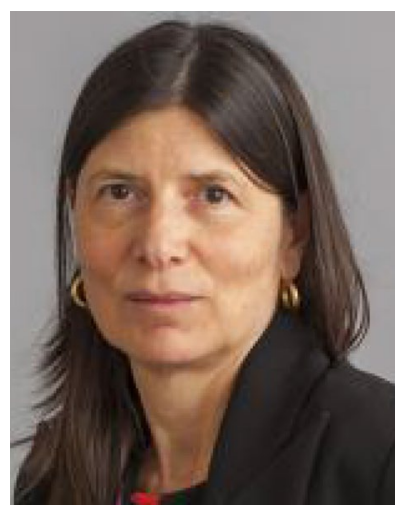

Elisabetta Ceretti is Full Professor in Manufacturing at the University of Brescia. She graduated in Mechanical Engineering at the University of Brescia. Her scientific activity is mainly focused on manufacturing process such as sheet incremental forming, machining operations, cold forming and ultraprecision machining processes.

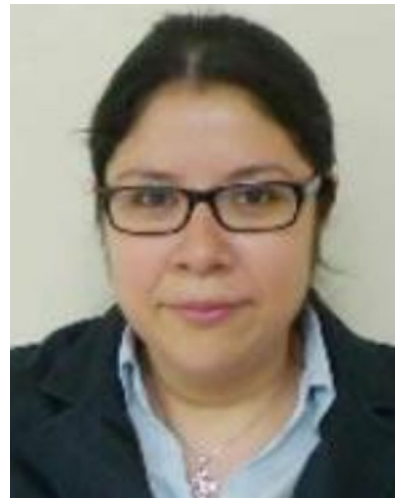

Erika García-López received the Electronics Engineer degree from Tecnologico de Veracruz. She obtained her MSc in Manufacturing Systems and her Ph.D. in Engineering Sciences from Tecnologico de Monterrey. Her research line is focused on micro-milling and laser technologies for medical devices manufacturing. 